\title{
Romatoid Artrit'in işitme ve vestibüler sistem üzerine etkileri
}

\section{Effects of rheumatoid arthritis on hearing and vestibular system}

\author{
Oğuzhan Dikiciıı, Nuray BAYAR MULUK 2a
}

'Şevket Yılmaz Eğitim ve Araştırma Hastanesi, KBB Kliniği, Bursa,

${ }^{2}$ Kırıkkale Üniversitesi Tıp Fakültesi, KBB Anabilim Dalı, Kırıkkale, TÜRKiYE

\section{ÖZET}

Romatoid artrit (RA), CD4 (+) T hücreleri ve monositlerin, damardan inflamasyonlu sinoviyal dokuya ve sinoviyal sıviya geçmesiyle karakterize, otoimmün bir hastalıktır. RA'nın işitmeye olan etkisi tartışılmaya devam etmektedir. İşitme kaybı sadece sensörinöral veya iletim tipinde olabilir. Ayrıca mikst tip işitme kaybı şeklinde de görülebilmektedir. İletim tipi işitme kaybı, timpano-ossiküler sistemin etkilenmesi ile ortaya çıkmaktadır. Sensörinöral kayıp ise nörit, vaskülit veya hastalığın tedavisi sırasında kullanılan ilaçların ototoksik etkilerine bağlı olarak ortaya çıkabilmektedir. RA, işitme bozukluğuna ek olarak vestibuler sistem bozukluğuna da sebep olabilmektedir. Vestibuler bozukluğun fizyolojisi tam açıklanamamıştır. Bu derlemede, RA'nın işitme ve vestibüler sistem üzerindeki etkileri, literatür bilgileri ışığında sunulmuştur.

Anahtar kelimeler: Romatoid artrit, işitme, iletim tipi işitme kaybı, sensörinöral tip işitme kaybı, vaskülit, vestibüler bozukluk

\section{ABSTRACT}

Rheumatoid arthritis (RA) is an autoimmune disease which is characterized by the passage of primarily CD4 (+) T cells and monocytes into the intravenous inflamed synovial tissue and synovial fluid. The effect of RA on hearing is an issue being discussed. Hearing loss can be conductive, sensorineural or mixed. Conductive hearing loss occurs with the involvement of tympano-ossicular system. Sensorineural hearing loss may have arisen due to the neuritis, vasculitis or ototoxic effects of the drugs used during the treatment. In addition to hearing disorders, RA may also cause vestibular system disorders. Pathophysiology of the vestibular disorders are still unclear. In this review, the effects of RA on hearing and vestibular system were presented with the literature survey.

Key words: Rheumatoid artritis, hearing, conductive hearing loss, Sensorineural hearing loss, vasculitis, vestibular disorder 


\section{Giriş}

Appelboom ve Halberg'in [1] bildirdiğine göre RA terimi tarihte ilk olarak İngiltere'de Sir Alfred Baring Garrod (1819-1907) tarafından 1859 yılında kullanılmıştır. RA, \%1-3 oranında erişkinlerde en sık görülen otoimmün hastalıktır. Eklemleri tutan kronik inflamatuar bir hastalıktır. Etyolojisi tam olarak açıklanamamıştır. Sıklıkla 35-45 yaş arasında, kadınlarda erkeklerden üç kat daha sık görülmektedir. Yorgunluk, halsizlik, kilo kaybı, terleme ve taşikardi en sık rastlanan semptomlarıdır. Ellerde metakarpofalangeal ve interfalangeal eklemlerde sabah sertliği şikayetleri tipiktir. Eklem şikayetleri halen hastalığın en sıkıntılı bölümü olup bunun yanısıra kaslarda güçsüzlük, bursit, nodüller, anemi ve lökopeni de görülebilmektedir [2].

Primer olarak CD4 (+) T hücrelerin ve monositlerin damardan inflamasyonlu sinoviyal doku ve sinoviyal sıvıya geçişi ile karakterizedir. Antijen tarafından aktive edilen CD4 (+) T hücreler, makrofaj ve fibroblastları stimüle ederek sinoviyal proliferasyon, pannus formasyonu, kemik ve kartilaj erozyonu, kronik inflamasyon ve yıkıcı eklem hastalığına sebep olan maddeleri salgılarlar [3,4]. Diartrodial eklem sinoviyal membranlarının inflamasyonuna bağlı olarak kartilaj yıkımı, kemik erimesi, ligamanların, tendonların ve eklem kapsüllerinin zayıflaması ve yıkımı ortaya çıkar. Mononükleer hücrelerin perivasküler infiltrasyonu sonucu oluşan vaskülit ve sonrasında gelişen sinoviyal kapsüldeki hücrelerin çoğalması sinovitin patolojik alt yapısını oluşturur $[4,5]$.

\section{Romatoid Artrit ve Sistemik Tutulum}

RA'da multisistemik tutulum söz konusudur. RA'da görülen ekstraartiküler tutulum yerleri kalp, akciğer, deri ve gözdür. Başboyun bölgesinde; temporomandibuler eklem, larinks, servikal omurga ve odyovestibüler sistem etkilenebilmektedir $[3,6]$.

\section{Romatoid Artrit ve İşitme}

RA'ı hastalarda işitme kaybı tartışılan bir konudur. Fizyopatolojisi tam olarak açıklanamamıştır. Bazı yazarlar işitme kaybının sensörinöral olduğunu ifade ederken, diğerleri iletim tipinde olduğunu düşünmektedirler. RA'nın ilk olarak orta kulağı etkilediği düşünülmektedir. RA'nın, inkudomalleolar ve inkudostapedial eklemleri etkileyerek, ossiküler mekanizmanın cevabını değiştirip iletim tipi işitme kaybına yol açtığı düşünülmektedir [7-11]. RA sürecinde bu eklemlerde fibröz psödoartroz gelişmektedir. Eklemlerdeki ankiloz kemikçik hareketlerinde azalmaya yol açarken, daha önemli olan piston etkisi değişmemektedir [2]. RA, mononöritis multipleks türü vaskülit ile işitsel nöropatiye neden olabilir. Otoimmünite, koklear saçlı hücrelerin tahribine veya iç kulakta immün depozit birikimine sebep olabilmektedir. RA tedavisinde kullanılan ilaçlar iç kulağı etkileyebilmektedirler [5,12].

\section{Illetim Tipi İşitme Kaybı}

İletim tipi işitme kaybı prevalansının, \%0,0-17,4 arasında olduğu bildirilmiştir $[4,13,14]$. RA'da iletim tipi işitme kaybı, orta kulaktaki eklemlerin hareket bozukluğu veya kemikçiklerin bütünlüğünün bozulmasına bağlı olabilir. İnkudomallear ve inkudostapedial eklemler, gerçek diartrodial eklem yapısındadır ve bundan dolayı RA tarafından etkilenebilmektedirler. Hastalığın diğer bir karakteristiği olan vaskülit, kemikçiklerin özellikle inkus uzun kolunun yetersiz perfüzyonuna yol açabilir ve bu yapının nekrozu sonucunda kemikçik zincir bütünlüğü bozulabilmektedir [4]. Colletti ve ark. [4], iletim tipi işitme kaybının kemikçik sistemdeki hareket bozukluğundan kaynaklandığını bildirmişlerdir. Reiter ve ark. [15], RA'lı hastalarda 0,25 ve 0,5 kHz'de 30-35 dB iletim tipi işitme kaybı olduğunu belirtmişlerdir.

Goodwill ve ark. [16], orta kulak kemikçiklerinde ve eklemlerinde romatoid nodül veya eklemlerde aşınma tarzında değişiklikler ve etkilenme olduğunu gösteren herhangi bir bulgu görememişlerdir. Bununla birlikte, bir vakada eklemde, inkus uzun kolunda ve lentiküler proseste yoğun kemik harabiyetinin olduğunu bildirmişlerdir [16]. RA'nın kemikçiklerdeki eklemleri etkiliyebileceği görüşü mantıklı bulunmuş ve Gussen [9] tarafından patolojik kanıtlar ortaya konmuştur. Inkudostapedial ve inkudomalleolar eklemlerin sellüler kollajenöz doku ile yer değiştirdiği ileri sürülmüştür. Bununla beraber RA'da tipik olan lenfosit ve plazma hücre infiltrasyonuna ait bir kanıt gösterilememiştir.

Copeman [17], iletim tipi işitme kaybının hastalığın aktivitesi ile ilişkili olduğunu belirtmiş ve osteoartrit terimini kullanmıştır. Moffat ve ark. [10], iletim tipi işitme kaybı olmayan RA'lı hastalarda oto-admitansı timpanogramla incelediği çalışmalarında, RA'lı kulakların \%38'inde, 660 Hz'de belirgin çentik mevcutken, kontrol grubundaki kulakların \%8'inde bu bulgunun mevcut olduğunu saptamışlardır. Timpanogramda saptanan çentikli kavsi, kemikçik sistem hareketindeki artmaya bağlamışlardır. Buna karşılık diğer yazarlar, kemikçik sistemde harekette azalma bulmuşlardır [13,15]. Rosenberg ve ark. [18], RA'lı hastaların kulaklarında \% 42 oranında ve kontrol grubunda ise $\% 7$ oranında aynı anormalliği bulduklarını bildirmişlerdir. Ortaya çıkan sonuç, orta kulak iletim sistemindeki yetersizliğe bağlanmıştır [19]. Elwany ve ark.'nın [13] timpanometri uyguladığı 68 RA'lı hastada, $220 \mathrm{~Hz}$ saf ses kullanıldığında, kulakların \%56'sında kemikçik sisteminde hareket bozukluğu olduğunu görmüşlerdir. Bu çalışmada 1 (\% 1,5) hastada iletim tipi işitme kaybı saptanmıştır.

Coletti ve ark. [4], multipl frekans timpanometri ile yaptıkları çalışmalarında, RA'lı hastalarının \%40'ında kemikçik sistemde sertlikte artma tespit etmişlerdir. Bu sonuç kemikçik zincirde ankiloza veya eklemlerden biri veya her ikisinin mobilitesinin azalmasına bağlı olabilir. Kakani ve ark. [19], çalışmalarında \%10 oranında anormal timpanogram tespit etmişlerdir. Bu timpanogramların tümünün As tipinde olduğu bildirilmiştir. Bu durum kompliansta azalma ve timpanoossiküler sistemin sertliğinde artma şeklinde yorumlanmıştır. Etholm ve Belal [20], kemikçik zincirdeki ankilozun pozitif odyometrik bulgularla birlikte olmayabileceğini belirtmişlerdir. Bununla birlikte kemikçiklerdeki fiziksel değişiklikler, işitme kaybından önce 
ortaya çıkan kemikçiklerdeki sürtünme rezistansının yükselmesine bağlanmıştır [13]. Tunçel ve ark. [21] stapes refleksi alınamayan RA'lı hastaların komplians değerlerinin, alınan hastalara göre daha düşük olduğunu görmüşlerdir.

\section{Sensörinöral Tip İşitme Kaybı}

RA'da, hem iletim tipi hem de sensörinöral tip işitme kaybı olduğu bildirilmekle birlikte, sensörinöral işitme kaybının daha fazla olduğu vurgulanmaktadır [13,19,22]. RA'da sensörinöral işitme kaybı prevalansının \%0-60 arasında olduğu bildirilmektedir. Sensörinöral işitme kaybının koklear değişikliklere bağlı olduğu belirtilmiştir [4,14,15]. RA'nın retrokoklear etkisine dair bulgu yazarların çoğunluğu tarafından saptanamamışken Magaro saptamıştır [13,22,23]. Özcan ve ark. [24], işitme kaybı ile yaş, hastalık süresi, romatoid faktör varlığı, kullanılan tedavi tipi ve eritrosit sedimentasyon hızı arasında korelasyon olmadığını bildirmişlerdir.

Kakani ve ark. [19] RA'lı hastaların \% 4'ünde mikst tip işitme kaybı bulmuşlardır. Salvinelli ve ark. [25], RA'lı hastalarda iletim tipi ve sensörinöral işitme kaybının birlikte görüleceğini belirtmiştir.

Heyworth ve ark. [7], yaptıkları çalışmada RA'lı hastalarda \%36,4 oranında sensörinöral işitme kaybı tespit etmekle birlikte; RA'nın kemikçik zinciri etkilediğine dair bir bulgu elde edememişlerdir. RA'nın hipotetik olarak arterit veya nöropati yolu ile sensörinöral veya labirentin fonksiyon bozukluğuna sebep olduğu düşünülmüştür. Callejo ve ark. [26] , RA'lı hastalarda $\% 42,7$ oranında işitme kaybı tespit etmişlerdir. Bu hastaların \%38,6'sında sensörinöral işitme kaybı da tespit edilmiştir.

Öztürk ve ark. [27], RA'lı hastalarda özellikle yüksek frekansları tutan sensörinöral işitme kaybı tespit etmişlerdir. Şahin ve ark. [28], RA'ı ı hastalarda düşük oranda da olsa sensörinöral, iletim ve mikst tip işitme kaybı tespit etmekle birlikte kontrol grubu ile anlamlı bir fark olmadığını belirtmişlerdir. Baradaranfar ve ark. [29], 8000 Hz'deki işitme kaybının sensörinöral olduğunu ve akustik refleks kaybının orta kulağın etkilenmesine bağlı olduğunu belirtmişlerdir.

Murdin ve ark. [11], RA'ı hastaların büyük çoğunluğunda Transiently Evoked Otoacoustic Emission (TEOAE)'ların olmadığını görmüşlerdir. Bu durumun erken asemptomatik işitme kaybının göstergesi olabileceğini düşünmüşlerdir. Ashok ve ark. [30] romatoid faktör ve işitme kaybını inceledikleri araştırmalarında, romatoid faktör pozitif olan hastaların \%27'sinde Distortion Product Otoacoustic Emission (DPOAE) alamamışlardır. Dikici ve ark. [31] TEOAE 1,0 / 1,5 / 2,0 ve 3,0 kHz amplitüd değerlerinde anlamlı derecede düşüş, ipsilateral stapes refleks $1,0 \mathrm{kHz}$ eşik değerlerinde anlamlı olarak yükseliş bulmuşlardır.

\section{Romatoid Artrit Aktivitesi ve İşitme}

RA aktivitesi ve işitmeye olan etkisi tartışılan bir konudur. Goodwill ve ark. [16], eritrosit sedimentasyon hızı ile belirlenen RA aktivitesi ve işitme kaybı arasında bir ilişki bulamamışlardır. Aynı şekilde Elwany [13] ve Murdin ve ark. [12], işitme eşikleri ile hastalık aktivitesi ve diğer romatolojik parametreler arasında ilişki saptayamamışlardır. Bununla birlikte romatoid nodüller ile işitme kaybı arasında bir ilişki olduğunu bildirmişlerdir. Buna karşıt olarak hastalığın alevlenme dönemlerinde iletim veya sensörinöral tipi işitme kaybının olabileceğini belirten yayınlar da mevcuttur [17,22].

\section{Romatoid Artrit ve Denge Sistemi}

RA'nın işitmeye etkisi kadar denge sistemine olan etkisi de araştırma konusu olmuştur. King ve ark. [32] RA'ı hastaların görsel vestibuler fonksiyonlarını inceledikleri araştırmalarında, hastalarda anlamlı bir hasar bulgusu olmadığını görmüşlerdir. RA'ı hastalarda denge bozukluğu olduğuna yönelik araştırmalar da mevcuttur. İlk olarak Ferrara ve ark. [33] RA'lı hastalarda RA evresi ve yaştan bağımsız olarak ortaya çıkan supratentoriyal santral vestibuler değişiklikleri tespit etmişlerdir. Buna ek olarak Yılmaz [34] ve Özkırış ve ark. [35], RA'ya bağlı vestibuler sistem bozukluğunun diğer çalışmalarda tespit edilenden daha yaygın olduğunu görmüşlerdir.

\section{Sonuç}

RA, sensörinöral veya iletim tipi işitme kaybına ve denge bozukluğuna sebep olabilmektedir. İşitme kaybı sadece sensörinöral veya iletim tipinde olabileceği gibi mikst tipte de olabilmektedir. İletim tipi işitme kaybı timpano-ossiküler eklemlerde hareket azalmasına bağlı ortaya çıkarken sensörinöral işitme kaybı nörit, vaskülit veya hastalığın tedavisi sırasında kullanılan ilaçların ototoksik etkilerine bağlı olabilmektedir. Hastalığın aktivite dönemlerinde iştmenin daha çok etkilenebileceği unutulmamalıdır. RA işitme bozukluklarının yanında vestibüler sistem bozukluğuna da sebep olabilmektedir. RA'ya bağlı denge bozukluğunda fizyopatoloji açık değildir. Bu konuda yapılacak araştırmalar ile hastalığın tedavisinde başarı yükseltilebilecektir.

\section{Çıkar çatışması ve Finansman Beyanı}

Bu çalışmada çıkar çatışması ve finansman destek alındığı beyan edilmemiştir.

\section{Kaynaklar}

1. Appelboom T, Halberg P. History. In: Hochberg M, Silman AJ, Smolen JS, Weinblatt ME, Weisman MH (eds). Rheumatology. 3rd Edition. Spain. The Mosby Company. 2003. p: 753-6.

2. Doğan M, Fişenk F. Romatoid Artritin Otorinolaringolojik Bulguları. K.B.B. ve Baş Boyun Cerrahisi Dergisi 1999; 7: 71-78.

3. Takatsu M, Higaki M, Kinoshita H, Mizushima Y, Koizuka I. Ear Involvement in Patients with Rheumatoid Arthritis. Otology \& Neurotology 2005; 26: 755-761.

4. Colletti V, Fiorino FG, Bruni L, Biasi D. Middle earmechanics in subjects with rheumatoid arthritis. Audiology 1997; 36: 136-146.

5. Dikici O. Romatoid Artritli Hastalarda Odyolojik Testler ve Geçici Uyarılmış Otoakustik Emisyonlar. Uzmanlık tezi, Kırıkkale, 2008.

6. Rigual NR. Otolaryngologic manifestations of rheumatoid arthritis. Ear Nose Throat J 1987; 66: 18-22. 
7. Heyworth T, Liyanage SP. A pilot survey of hearing loss in patients with rheumatoid arthritis. Scand J Rheumatol 1972; 1: 81-3.

8. Goodwill CJ, Lord IJ, Knill-Jones RP. Heraing in rheumatoid arthritis-result of audiometry in 76 patients. Ann Rheum Dis 1971 30: 329-31.

9. Gussen R. Atypical ossicle joint lesions in rheumatoid arthritis with sicca syndrome (Sjögren's syndrome). Arch Otolaryngol 1977; 103: 281-3.

10. Moffat DA, Ramsden RT, Rosenberg JN. Otoadmittance measurements in patients with rheumatoid arthritis. J Laryngol Otol 1977; 91: 917-27.

11. Biasi D, Fiorino F,Carletto A, Caramaschi P, Zeminian S. Milde ear function in rheumatoid arthritis: a multiple frequency tympanometric study. Clinical and Experimental Rheumatology1996; 14: 243-7.

12. Murdin L, Patel S, Walmsley J, Yeoh LH. Hearing difficulties are common in patients with rheumatoid arthritis. Clin Rheumato 2008; 27: 637-40.

13. Elwany S, El Garf A, Kamel T. Hearing and middle earfunction in rheumatoid arthritis. J Rheumatol 1986; 13: 878-81.

14. Raut VV, Cullen J. Hearin Loss in Rheumatoid Arthritis. The Journal of Otolaryngology 2001; 30: 289-94.

15. Reiter D, Konkle DF, Mayers AR. Middle ear immitance in rheumatoid artritis. Arch Otolaryngol 1980; 106: 114-7.

16. Goodwill CJ, Lord IJ, Knill-Jones RP. Hearing in rheumatoid arthritis; a clinical and audometric survey. Ann Rheum Dis 1972; 31: 170-3.

17. Copeman WSC. Rheumatoid otoarthritis? Br Med J 1963; 2: 1526-7.

18. Rosenberg JN, Moffat DA, Ramsden RT. Milde ear functions in rheumatoid arthritis. Ann Rheum Dis 1978; 37: 522-4.

19. Kakani RS, Mehra YN, Deodhar SD, Mehta S. Audiovestibular functions in Rheumatoid Arthritis. The Journal of Otolaryngology 1990; 19: 100-2.

20. Etholm B, Belal A. Senile changes in the middle ear joints. Ann Otol Rhinol Laryngol 1974; 84: 49-54.

21. Tunçel İ, Özkarakaş H, Aydın Ö, Dursun N, Dursun E, Akdeniz Ö. Romatoid Artritin Ortakulak Kemikçik Eklemleri Üzerindeki Etkilerine Odyometrik ve İmpedansmetrik Yaklaşım. PTT Hastanesi Tıp Dergisi. 1999; 21: 145-8.

22. Magaro $M$, Zoli A, Altomonte $L$, et. al. Sensorineural hearing loss in rheumatoid arthritis. Clin Exp Rheumatol 1990; 8: 487-90.

23. Kastanioudakis I, Skevas A, Danielidis V, Tsiakou E, DrososA, Moustopoulos $\mathrm{H}$. Inner ear involvement in rheumatoid arthritis: a prospective clinical study. J Laryngol Otol 1995; 109: 713-8.

24. Özcan $M$, Karakus MF, Gündüz $\mathrm{OH}$, Tuncel Ü, Şahin $\mathrm{H}$. Hearing loss and middle ear involvement in rheumatoid arthritis. Rheumatol Int 2002; 22: 16-9.

25. Salvinelli F, D'Ascanio L, Casale M, Vadacca M, Rigon A, Afeltra A. Auditory pathway in rheumatoid arthritis. A comparative study and surgical perspectives. Acta Otolaryngol. 2006; 126: 32-6.

26. Callejo FJG, TobíasNC, NM Fernández, CPVernetta, IA Castañeira, JM Algarra. Hearing Impairment in Patients With Rheumatoid Arthritis. Acta Otorrinolaringol Esp. 2007; 58: 232-8.

27. Oztürk A, Yalçin S, Kaygusuz I, ve ark. High-frequency hearing loss and middle ear involvement in rheumatoid arthritis. Am J Otolaryngol. 2004; 25: 411-7.

28. Şahin L, Özdemir İ, Çallı Ç, Kopar A, Sezgin K, Pınar E. Romatoid Artritte Orta Kulak Eklemlerinin Tutulumunun Odyometrik Açıdan Değerlendirilmesi. Turkish Archives of Otolaryngology. 2004; 42: 204-9.

29. Baradaranfar MH, Doosti A. A survey of relationship between rheumatoid arthritis and hearing disorders. Acta Med Iran 2010; 48: 371-3.

30. Ashok Murthy V, Mohan Kumar J. Rheumatoid factor and hearing loss. Indian J Otolaryngol Head Neck Surg 2012; 64: 364-5.

31. Dikici O, Muluk NB, Tosun AK, Unlusoy I. Subjective audiological tests and transient evoked otoacoustic emissions in patients with rheumatoid arthritis: analysis of the factors affecting hearing levels. Eur Arch Otorhinolaryngol 2009; 266: 1719-26.

32. King J, Young C, Highton J, Smith PF, Darlington CL. Vestibuloocular, optokinetic and postural function in humans with rheumatoid arthritis. Neurosci Lett. 2002; 328: 77-80.

33. Ferrara P, Modica A, Adelfio M, Salli L, Pappalardo A. Audio-vestibular changes in patients with rheumatoid arthritis. Minerva Med. 1988; 79: 1043-7.

34. Yilmaz S, Erbek S, Erbek SS, Ozgirgin N, Yucel E. Abnormal electronystagmography in rheumatoid arthritis. Auris Nasus Larynx. 2007; 34: 307-11.

35. Özkırış M, Kapusuz Z, Günaydın I, Kubilay U, Pırtı İ, Saydam L. Does rheumatoid arthritis have an effect on audiovestibular tests? Eur Arch Otorhinolaryngol. 2014; 271: 1383-7. 